\title{
Effect of exercise-induced neurogenesis on cognitive function deficit in a rat model of vascular dementia
}

\author{
DONG-HEE CHOI ${ }^{1,2}$, KYOUNG-HEE LEE ${ }^{2}$ and JONGMIN LEE ${ }^{2,3}$ \\ ${ }^{1}$ Department of Medical Science, Konkuk University School of Medicine; ${ }^{2}$ Center for Neuroscience Research, \\ Institute of Biomedical Science and Technology, Konkuk University; ${ }^{3}$ Department of Rehabilitation Medicine, \\ Konkuk University School of Medicine and Konkuk University Medical Center, Seoul 143-701, Republic of Korea
}

Received March 10, 2015; Accepted January 14, 2016

DOI: $10.3892 / \mathrm{mmr} .2016 .4891$

\begin{abstract}
Chronic cerebral hypoperfusion $(\mathrm{CCH})$ is strongly correlated with progressive cognitive decline in neurological diseases, such as vascular dementia (VaD) and Alzheimer's disease. Exercise can enhance learning and memory, and delay age-related cognitive decline. However, exercise-induced hippocampal neurogenesis in experimental animals submitted to $\mathrm{CCH}$ has not been investigated. The present study aimed to investigate whether hippocampal neurogenesis induced by exercise can improve cognitive deficit in a rat model of VaD. Male Wistar rats (age, 8 weeks; weight, 292 $\pm 3.05 \mathrm{~g}$; $\mathrm{n}=12-13$ /group) were subjected to bilateral common carotid artery occlusion (2VO) or sham-surgery and each group was then subdivided randomly into no exercise and treadmill exercise groups. Exercise groups performed treadmill exercise daily at $15 \mathrm{~m} / \mathrm{min}$ for $30 \mathrm{~min}$ for 4 weeks from the third to the seventh week after $2 \mathrm{VO}$. It was demonstrated that the number of neural progenitor cells and mature neurons in the subgranular zone of $2 \mathrm{VO}$ rats was increased by exercise, and cognitive impairment in $2 \mathrm{VO}$ rats was attenuated by treadmill exercise. In addition, mature brain-derived neurotrophic factor (BDNF) levels in the hippocampus were increased in the exercise groups. Thus the present study suggests that exercise delays cognitive decline by the enhancing neurogenesis and increasing BDNF expression in the context of $\mathrm{VaD}$.
\end{abstract}

\section{Introduction}

Vascular dementia ( $\mathrm{VaD})$ is one of the most common cognitive disorders of the elderly, after Alzheimer's disease (AD). VaD is

Correspondence to: Professor Jongmin Lee, Department of Rehabilitation Medicine, Konkuk University School of Medicine and Konkuk University Medical Center, 120 Neungdong-ro, Gwangjin-gu, Seoul 143-701, Republic of Korea

E-mail: leej@kuh.ac.kr

Key words: chronic cerebral hypoperfusion, vascular dementia, treadmill exercise, spatial memory, brain-derived neurotrophic factor, neurogenesis caused by a range of cardiovascular or cerebrovascular conditions that lead to ischemic, hypoperfusive, or hemorrhagic brain lesions; which are characterized by a loss of cognitive function (1-4). Chronic cerebral hypoperfusion $(\mathrm{CCH})$ is strongly correlated with progressive cognitive decline $(5,6)$. Since the establishment of the $2 \mathrm{VO}$ rat model to reproduce $\mathrm{CCH}$, which is the permanent bilateral occlusion of the common carotid artery $(7,8)$, this model has been used widely to study the molecular mechanisms underlying cognitive impairment, white matter lesions, and neuronal damage observed in $\mathrm{CCH}$, as well as in therapeutic intervention studies (9-12).

Among the novel therapeutic strategies that have been pursued to alleviate cognitive damage, physical activity has been shown to support brain health and function through the prevention of oxidative stress $(13,14)$, with beneficial effects on learning, long-term potentiation and memory (14-16). Currently, regular physical activity is consistently indicated as a preventive measure for age-related neurodegenerative diseases $(14,17)$.

In the mammalian brain, neurogenesis continues throughout adulthood. Several factors, including exposure to environmental enrichment, exercise and ischemic insult, have been demonstrated to affect adult neurogenesis (18-20).

Exercise enhances neurogenesis, expression of growth factors and synaptic plasticity in the hippocampus of rodents (21). These changes have been associated with improved cognitive function, spatial memory and learning (21-24). In humans, physical activity not only improves cognitive function, but is also associated with a reduced risk of dementia, $\mathrm{AD}$, and cognitive impairment in elderly individuals (25-27).

In the adult brain, brain-derived neurotrophic factor (BDNF) is known to be important in synaptic plasticity, learning and neurogenesis, and is considered to be the most important factor to be upregulated by exercise $(14,28)$. Mature BDNF activates tyrosine receptor kinase $\mathrm{B}$, which is followed by the phosphorylation of downstream effectors, including protein kinase B, extracellular signal-regulated kinase, and calcium-calmodulin dependent kinase. Ultimately, the transcription factor cAMP-calcium response element binding protein (CREB), which mediates the transcription of genes that are essential for the survival and differentiation of neurons, is phosphorylated and activated $(14,29)$. Accumulating evidence indicates that a signaling mechanism is involved 
in neurogenesis augmentation, which is associated with the expression of phosphorylated CREB (p-CREB) and BDNF in the hippocampus (22), and is involved in synaptic plasticity, learning and memory (30). A previous study reported that physical activity, such as exercise, enhances ischemic neurogenesis following stroke (31).

However, the effect of physical activity-induced hippocampal neurogenesis in $\mathrm{VaD}$ has not been investigated. Therefore, in the present study, the effect of increased hippocampal neurogenesis induced by exercise on cognitive impairment was confirmed in rats subjected to $2 \mathrm{VO}$.

\section{Materials and methods}

Animals and experimental setup. A total of 52 adult male Wistar rats (age, 8 weeks; weight, 292 \pm 3.05 g; Samtako Bio Korea, Co., Ltd., Seorang-dong, Korea) were used in this study. The animals were housed in groups of 3 in smooth-bottomed plastic cages $(28 \times 42 \times 20 \mathrm{~cm})$ with beta chip bedding (Agrolab Group, Bavaria, Germany) in a specific pathogen free room that was maintained on a $12 \mathrm{~h}$ light/dark cycle. Food and water were available ad libitum. The room temperature was maintained at $22 \pm 1^{\circ} \mathrm{C}$ and the room was illuminated by incandescent lamps (luminous flux, $11.771 \mathrm{~m}$ ). To accustom the animals to the laboratory environment, an acclimation period of 1 week was allowed prior to the initiation of the experiment. Animal treatments, including anesthesia and euthanasia were conducted in accordance with the Principle of Laboratory Animal Care (NIH Publication no. 85-23, revised 1985). All experimental procedures were approved by the Animal Experiment Review Board of the Laboratory Animal Research Center of Konkuk University (Seoul, Korea; KU09059).

The experimental animals were randomly divided into 2 groups: The sham-surgery group [sham control (SC), $n=24]$ and the $2 \mathrm{VO}$ group $(\mathrm{n}=28)$. A blindness test was performed to exclude blind rats, as described previously (32), 3 weeks after surgery. The blindness rates were $10.7 \%$ (3 out of 28) among $2 \mathrm{VO}$ rats and $0 \%$ (0 out of 24) among the SC rats. Twenty-four rats from the SC group and 25 rats from the $2 \mathrm{VO}$ group were subdivided into treadmill exercise or no exercise groups. The experimental groups consisted of $\mathrm{SC}(\mathrm{n}=12), \mathrm{SC}$ with treadmill exercise $(\mathrm{SC}+\mathrm{EX}, \mathrm{n}=12), 2 \mathrm{VO}(\mathrm{n}=13)$, and $2 \mathrm{VO}$ with treadmill exercise (2VO+EX, $n=12)$.

A subset of animals were used for behavioral ( $n=12-13 /$ group), morphological ( $n=8 /$ group), and biochemical analysis ( $n=4-5 /$ group). The animals were number coded and investigators were always blinded to the treatment groups until the end of the data analysis. Animal allocation and a time line of experiments are shown in Fig. 1.

Surgical procedures. Chronic cerebral hypoperfusion in the rat was modeled by 2 VO. The rats were anesthetized with $70 \%$ nitrogen and $30 \%$ isoflurane (Hana Pharm Co., Ltd., Kyonggido, Korea). Both common carotid arteries were exposed through a midline cervical incision and were double ligated using silk sutures ( $\mathrm{n}=28$; B. Braun Medical Inc., Bethlehem, PA, USA). The SC rats $(n=24)$ were treated similarly to the rats in the $2 \mathrm{VO}$ group with the exception of the common carotid artery occlusion. During the surgical procedure, the rectal temperature was monitored and maintained at $37 \pm 0.5^{\circ} \mathrm{C}$ using a heating pad (Homeothermic Blanket system; Harvard Apparatus Inc., Holliston, MA, USA). Following surgery, rats were kept in an animal resource facility with access to food and water ad libitum. Three weeks after the sham or 2VO surgery, the rats underwent a blindness test as described previously (32), followed by treadmill exercise.

Forced treadmill training. The animals allocated to the exercise groups $(\mathrm{SC}+\mathrm{EX}$ and $2 \mathrm{VO}+\mathrm{EX})$ ran on a motor-driven treadmill (Columbus Instruments, Columbus, OH, USA) at a $0^{\circ}$ inclination, beginning 3 weeks after the sham or $2 \mathrm{VO}$ operation. The speed of the exercise was $15 \mathrm{~m} / \mathrm{min}$, and the animal performed exercise $30 \mathrm{~min}$ daily for 4 weeks (5 days/week). The electrical part of the treadmill delivered light electric shocks (about $0.3 \mathrm{~mA}$ stimulus current) when the rats entered the rear of the test chamber. The SC and 2VO groups were placed in neighboring lanes without switching on the treadmill motor for the exact duration of the experiments (33).

\section{5-Bromo-2-deoxyuridine (BrdU) administration.} Neurogenesis was assessed by analyzing the incorporation of BrdU (Sigma-Aldrich, St. Louis, MO, USA), which is a thymidine analog and a marker of proliferating cells. BrdU solutions were prepared to $5 \mathrm{mg} / \mathrm{ml}$ in sterile saline with $0.007 \mathrm{~N}$ $\mathrm{NaOH}$ to obtain a $50 \mathrm{mg} / \mathrm{kg}$ dose $(10 \mathrm{ml} / \mathrm{kg})$. The animals received an intraperitoneal (IP) injection of $50 \mathrm{mg} / \mathrm{kg} /$ day of BrdU (Sigma-Aldrich) 3 weeks following sham or $2 \mathrm{VO}$ surgery, and received the same dosage every day for 2 weeks ( $n=12-13 /$ group).

Morris water maze (MWM) test. The MWM test was used to evaluate learning and memory in rats $(11,34)$. The maze was a round tank that measured $1.83 \mathrm{~m}$ in diameter and was $0.58 \mathrm{~m}$ deep. It was filled to a depth of $35.5 \mathrm{~cm}$ with tepid $\left(26 \pm 1^{\circ} \mathrm{C}\right)$ water that was made opaque by the addition of a nontoxic white-colored dye. A movable circular platform with a diameter of $12 \mathrm{~cm}$ was placed $2 \mathrm{~cm}$ below the surface of the water. The maze was surrounded by white curtains, on which black visual stimuli of various shapes and sizes were placed. A camera (CBC Co., Ltd., Tokyo, Japan) was located above the center of the maze and relayed images to a videocassette recorder (AverMedia, New Taipei City, Taiwan) and an HVS Image Analysis Computer system (HVS, Hampton, United Kingdom). Seven weeks after sham or 2VO surgery (4 weeks after treadmill exercise), the MWM test was conducted to evaluate spatial memory ( $n=12-13 /$ group). Four consecutive sessions, each consisting of 5 trials over 1 day, were conducted over 4 consecutive days. The hidden platform was always placed in the southeast quadrant of the pool. Every trial started at a different point, which alternated among the 4 quadrants. Rats were gently handled for 10 min daily for 7 days prior to the test. In the maze, rats were allowed to swim for a maximum of $90 \mathrm{sec}$. If the rat failed to find the platform within $90 \mathrm{sec}$, it was guided gently onto the platform and allowed to remain there for $30 \mathrm{sec}$. The intertrial interval was $1 \mathrm{~min}$. Performance accuracy was evaluated by analyzing the search error and time latency data of all trials. Measurement of the search error was based on a computation of the average distance from the platform during the trial. The distance between a rat and the platform was sampled 10 times/sec during each trial, and these 
distances were averaged in $1 \mathrm{sec}$ bins. The cumulative search error was the sum of these $1 \mathrm{sec}$ averages of the proximity measure corrected for the specific platform location and start location, by subtracting the proximity score that would be produced by a perfect performance in the trial. A probe trial was conducted $1 \mathrm{~min}$ after the 5 th training trial at the 2nd and 4th sessions. The entire training procedure included 2 probe trials for each rat, during which the rats swam with the platform retracted to the bottom of the pool for $30 \mathrm{sec}$. After recording the swimming path, the platform was raised to its normal position for completion of the trial. Swimming time in the target quadrant of the retracted platform was used as a parameter of the retention of spatial memory.

Western blot analysis. Hippocampal tissues were washed with ice-cold phosphate-buffered saline (PBS) and lysed on ice in radioimmunoprecipitation assay buffer $[50 \mathrm{mM}$ Tris- $\mathrm{HCl}$, $\mathrm{pH} 7.4 ; 150 \mathrm{mM} \mathrm{NaCl}, 1 \% \mathrm{NP} 40,0.25 \%$ Na-deoxycholate, and $0.1 \%$ sodium dodecyl sulfate (SDS)] containing a protease inhibitor mixture and phosphatase inhibitors (Sigma-Aldrich). Soluble proteins $(30 \mu \mathrm{g})$ were subjected to 12\% SDS-polyacrylamide gel (Bio-Rad Laboratories, Inc., Berkeley, CA, USA) electrophoresis and electrotransferred onto a polyvinylidene difluoride membrane (Millipore, Darmstadt, Germany). Membranes were blocked for $1 \mathrm{~h}$ in $20 \mathrm{mM}$ Tris- $\mathrm{HCl}$ containing $137 \mathrm{mM} \mathrm{NaCl}$ and $0.1 \%$ Tween 20 (TBST) containing 5\% skim milk at room temperature. They were then incubated overnight at $4^{\circ} \mathrm{C}$ with the following primary antibodies: Rabbit polyclonal anti-rat BDNF antibody (cat. no. sc-546; Santa Cruz Biotechnology, Inc., Santa Cruz, CA, USA; 1:500), rabbit polyclonal anti-rat phosphorylated CREB antibody (cat. no. 9191; Cell Signaling Technology, Inc., Danvers, MA, USA; 1:1,000), rabbit polyclonal anti-rat-CREB antibody (cat. no. 9197; Cell Signaling Technology Inc.; 1:1,000), mouse monoclonal anti-rat $\beta$-actin antibody (cat. no. A5441; Sigma-Aldrich; 1:5,000). Membranes were washed with TBST and then incubated with peroxidase-conjugated AffiniPure goat anti-mouse IgG (H+L; cat. no. 115-035-003; Jackson ImmunoResearch, West Grove, PA, USA; 1:3,000 dilution) or peroxidase-conjugated AffiniPure goat anti-rabbit IgG $(\mathrm{H}+\mathrm{L}$; cat. no. 111-035-003; Jackson ImmunoResearch; 1:3,000) for $1 \mathrm{~h}$ at room temperature. Specific bands were detected using the ECL system (Amersham, Buckinghamshire, UK) and analyzed using the Bio-Rad electrophoresis image software (Bio-Rad Laboratories, Inc., Hemel Hampstead, UK). $\beta$-actin was used as a loading control and the band intensity was normalized to $\beta$-actin. Quantitative analysis was performed using quantity one software (version 4.6.6; Bio-Rad Laboratories, Inc.).

Immunohistochemistry. Rats were anesthetized with diethyl ether (>4.5\%; Samchun Pure Chemical, Kyonggido, Korea) and sacrificed by transcardial perfusion following anesthesia with diethyl ether. Rats were transcardially perfused with saline containing $0.5 \%$ sodium nitrite (Sigma-Aldrich) and $10 \mathrm{U} / \mathrm{ml}$ heparin sulfate (Jeil Pharmaceutical Co., Ltd., Seoul, Korea), followed by $4 \%$ cold formaldehyde (Sigma-Aldrich) generated from paraformaldehyde in $0.1 \mathrm{M} \mathrm{PBS}(\mathrm{pH} 7.2)$. Following perfusion, rats were decapitated and then the brains were removed and hippocampus blocks were immersion fixed in $4 \%$ paraformaldehyde and cryoprotected in sucrose. Serial coronal sections $(40 \mu \mathrm{m})$ were cut on a cryostat, collected in cryopreservative (Sigma-Aldrich), and stored at $-20^{\circ} \mathrm{C}$. Tissue sections were washed in 0.1 M PBS and endogenous peroxidase was blocked by immersing sections in $0.3 \% \mathrm{H}_{2} \mathrm{O}_{2}$ in $0.1 \mathrm{M}$ PBS for $30 \mathrm{~min}$. To denature DNA, brain sections were incubated in $50 \%$ formamide in saline sodium citrate buffer (2X SSC, $0.3 \mathrm{M} \mathrm{NaCl}$ buffer, and $0.03 \mathrm{M}$ trisodium citrate) at $60^{\circ} \mathrm{C}$ for $2 \mathrm{~h}$, followed by incubation at $37^{\circ} \mathrm{C}$ in $2 \mathrm{~N} \mathrm{HCl}$ for $30 \mathrm{~min}$, and rinsing in $100 \mathrm{mM}$ boric acid (pH 8.5) for $10 \mathrm{~min}$. Sections were washed in $0.1 \mathrm{M}$ PBS, and then incubated in $0.1 \mathrm{M}$ PBS containing 5\% normal goat serum (Jackson ImmunoResearch) and 0.3\% Triton X-100 (Sigma-Aldrich) for $1 \mathrm{~h}$, and subsequently incubated overnight with a rat anti-BrdU antibody (BrdU, 1:400: Abcam, Cambridge, MA, USA) at $4^{\circ} \mathrm{C}$. The sections were then incubated with biotinylated anti-rat IgG (1:500; cat. no. BA-9400; Vector Laboratories, Burlingame, CA, USA) for $1 \mathrm{~h}$, followed by avidin/biotin/peroxidase (1:50; Vector Laboratories) staining for $1 \mathrm{~h}$ in a humidified chamber. PBS $(0.1 \mathrm{M})$ containing $1.5 \%$ bovine serum albumin (Sigma-Aldrich) was used to wash sections on slides between all steps. The antigen-antibody complexes were visualized by incubation for $5 \mathrm{~min}$ in $0.05 \% 3,3^{\prime}$-diaminobenzidine (Sigma-Aldrich) and $0.003 \% \mathrm{H}_{2} \mathrm{O}_{2}$ (Sigma-Aldrich), and sections were then mounted sequentially on glass slides using permanent mounting medium (Vector Laboratories). Mounted sections were evaluated using a light microscope (Eclipse 80i; Nikon, Tokyo, Japan).

Fluorescent immunostaining of tissues. Brain sections were incubated in antigen retrieval buffer including 50\% formamide in saline sodium citrate buffer ( $2 \mathrm{X} \mathrm{SSC}, 0.3 \mathrm{M} \mathrm{NaCl}$ buffer, and $0.03 \mathrm{M}$ trisodium citrate) at $60^{\circ} \mathrm{C}$ for $2 \mathrm{~h}$. To denature DNA, brain sections were incubated at $37^{\circ} \mathrm{C}$ in $2 \mathrm{~N} \mathrm{HCl}$ for $30 \mathrm{~min}$ and rinsed in $100 \mathrm{mM}$ boric acid $(\mathrm{pH} 8.5)$ for $10 \mathrm{~min}$. Brain sections $(40 \mu \mathrm{m})$ were washed in $0.1 \mathrm{M}$ PBS, incubated in $0.1 \mathrm{M}$ PBS containing 5\% normal donkey serum (Jackson ImmunoResearch) and $0.3 \%$ Triton $\mathrm{X}-100$ for $1 \mathrm{~h}$, and subsequently incubated overnight at $4{ }^{\circ} \mathrm{C}$ with primary antibodies, including mouse monoclonal anti-rat NeuN (1:2,000; cat. no. MAB377; Millipore, Billerica, MA, USA), goat monoclonal anti-rat doublecortin (DCX; 1:500; cat. no. sc-8066; Santa Cruz Biotechnology, Inc.) and rat monoclonal anti-BrdU (1:400; cat. no. ab6326; Abcam) in 2\% normal donkey serum (Jackson ImmunoResearch) in PBS. Subsequently, they were incubated in a 1:200 dilution of Alexa Fluor-conjugated 488 donkey anti-mouse IgG (H+L; cat. no. A21202; Invitrogen; Thermo Fisher Scientific, Inc.), Alexa Fluor-conjugated 488 donkey anti-goat IgG (H+L; cat. no. A11055; Invitrogen; Thermo Fisher Scientific, Inc.) or Alexa Fluor-conjugated 647 chicken anti-rat IgG (H+L; cat. no. A21472; Invitrogen; Thermo Fisher Scientific, Inc.) for $1 \mathrm{~h}$ at room temperature, washed with PBS, and mounted sequentially on glass slides using Vectashield (Vector Laboratories). Mounted sections were evaluated for fluorescence under settings for 488 and 647 emissions on a confocal microscope (FV-1000 spectral; Olympus, Melville, NY, USA). Quantitative analysis was performed.

Quantitative analysis. Sections including the hippocampus from 8 rats per group were subjected to analysis. Five regions 


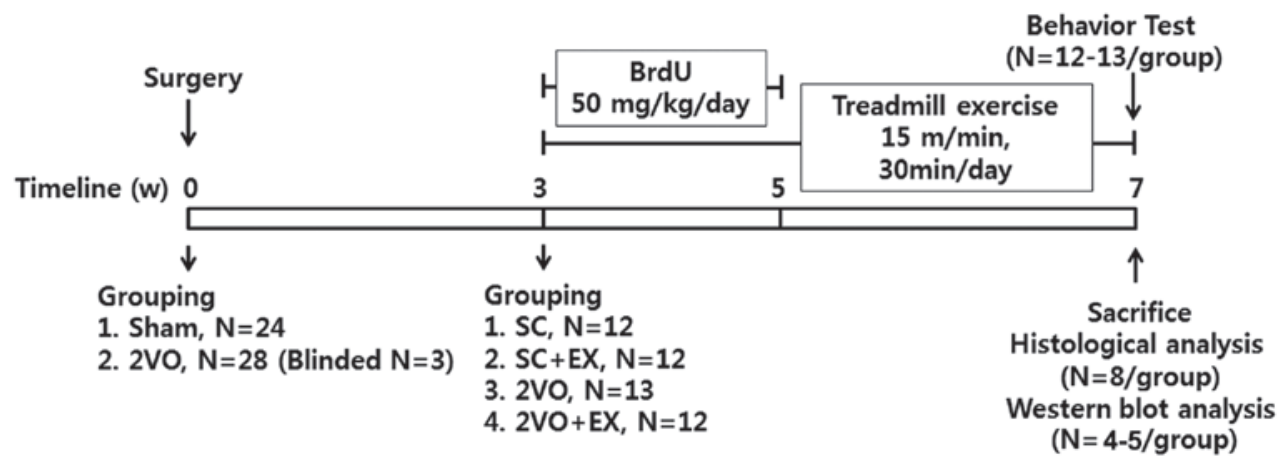

Figure 1. Animal allocation and time line for experiments for rats submitted to sham or $2 \mathrm{VO}$. Rats underwent treadmill exercise daily at $15 \mathrm{~m} / \mathrm{min}$ for $30 \mathrm{~min}$ for 4 weeks 3 weeks after sham or 2VO surgery. 2VO. SC, sham-surgery group; SC+EX, sham-surgery group subjected to treadmill exercise (15 m/min, $30 \mathrm{~min} / \mathrm{day}$ for 4 weeks); 2VO, 2VO surgery group; 2VO+EX, 2VO-surgery group subjected to treadmill exercise ( $15 \mathrm{~m} / \mathrm{min}, 30 \mathrm{~min} / \mathrm{day}$ for $4 \mathrm{weeks})$.

of interest (ROI) of $0.25 \mathrm{~mm}^{2} /$ section in the subgranular zone (SGZ) of the hippocampus (bregma -3.30 to $-4.30 \mathrm{~mm}$; 5 sections per rat, every 5 th section) were selected. The number of $\mathrm{BrdU}^{+}, \mathrm{DCX}^{+}, \mathrm{NeuN}^{+}, \mathrm{BrdU}^{+}$and $\mathrm{DCX}^{+}$, or $\mathrm{BrdU}^{+}$ and $\mathrm{NeuN}^{+}$cells was counted in each ROI, and averaged. Data are presented as the percentage of total cells. All quantitative analyses were conducted in a blinded manner.

Statistical analysis. Parameters relating to spatial memory, including the search error, time latency, and swimming speed, were analyzed by two-way repeated measures analysis of variance (ANOVA), followed by a post hoc least significant differences multiple-comparison test. One-way ANOVA was used to compare the results of the probe trials and the quantitative data of the western blot analysis and immunohistochemistry (mean \pm standard error of the mean). Statistical analysis was performed using one-way ANOVA followed by the Newman-Keuls multiple comparison test. $\mathrm{P}<0.05$ was considered to indicate a statistically significant difference. Data analyses were performed using the IBM SPSS statistics 22 (IBM Corporation, Armonk, NY, USA).

\section{Results}

Treadmill exercise reduces the memory impairment induced by $\mathrm{CCH}$. To evaluate the effect of exercise on the recovery of cognitive function after $2 \mathrm{VO}$, spatial memory was evaluated by assessing learning and memory retention using the MWM test. In the acquisition trials, the rats in the SC group gradually learned the location of the hidden platform, which was demonstrated by the shorter latencies and fewer search errors recorded throughout the test period. $\mathrm{CCH}$ induced by $2 \mathrm{VO}$ resulted in a significant impairment in spatial learning [time latency, $\mathrm{F}(3,44)=13.78$; and search errors, $F(3,44)=11.63]$ compared with that observed for the SC group (repeated-measures two-way ANOVA, P<0.01; Fig. 2A and B). Exercise-treated $2 \mathrm{VO}$ animals exhibited shorter mean session latencies and fewer search errors in locating the platform compared with the $2 \mathrm{VO}$ group (repeated measures two-way ANOVA, $\mathrm{P}<0.05$; Fig. $2 \mathrm{~A}$ and $\mathrm{B}$ ). To determine whether the group differences observed in escape latencies were caused by differences in swimming, particularly between the SC group and the $2 \mathrm{VO}$ group, swimming speeds were calculated for each group. No differences in swimming speed were observed among the four groups [repeated measures two-way ANOVA, $\mathrm{F}(3,44)=0.329$; Fig. $2 \mathrm{C}$ ]. In addition, differences in performance were observed during the probe trial, as assessed by the percentage of time spent in the target quadrant during the $30 \mathrm{sec}$ probe trial (Fig. 2D). One-way ANOVA of the time spent in the target quadrant observed on the second probe trial showed that the between-group effects were significant. Post hoc analysis revealed that $2 \mathrm{VO}$ rats that were subjected to treadmill exercise exhibited significant improvements during the probe trials compared with $2 \mathrm{VO}$ rats (percentage of time spent in the target quadrant, $\mathrm{P}<0.05$, Fig. 2D).

Treadmill exercise increases hippocampal neurogenesis. Rats received an injection of the cell proliferation marker BrdU (50 mg/kg, IP injection, once a day) 3-5 weeks after surgery. At 7 weeks after surgery, the majority of $\mathrm{BrdU}^{+}$cells were localized in the SGZ of the hippocampus (Fig. 3). The number of $\mathrm{BrdU}^{+}$cells was significantly increased in the $\mathrm{SGZ}$ of rats in the SC+EX and 2VO+EX groups (Fig. 3B).

In order to examine the effect of exercise on 2VO-induced cell proliferation, BrdU and DCX double-labeling methods were used to detect proliferating cells in the hippocampal SGZ of rats in the 2VO-EX and SC-EX groups. The number of $\mathrm{BrdU}^{+}$cells, $\mathrm{DCX}^{+}$cells, and $\mathrm{BrdU}^{+}$and $\mathrm{DCX}^{+}$cells in the $\mathrm{SGZ}$ of the rats in the SC+EX and 2VO+EX groups was increased compared with that observed in the $\mathrm{SC}$ and $2 \mathrm{VO}$ groups, respectively ( $\mathrm{P}<0.001$ vs. SC; $\mathrm{P}<0.05$ vs. $2 \mathrm{VO}$; Fig. 4). These results suggest that exercise increases the proliferation of immature neurons in the SGZ of the chronically hypoperfused rats. Next, in order to examine the effect of exercise on the differentiation of progenitor cells in chronically hypoperfused rats, BrdU- and NeuN-labeling methods were used to detect differentiated cells in the SGZ of the SC+EX and 2VO+EX rats. The number of $\mathrm{BrdU}^{+}$and $\mathrm{BrdU}^{+}$and $\mathrm{NeuN}^{+}$double-labeled cells in the SGZ of the $\mathrm{SC}+\mathrm{EX}$ and $2 \mathrm{VO}+\mathrm{EX}$ rats were increased compared with that observed for $\mathrm{SC}$ and $2 \mathrm{VO}$ rats, respectively ( $\mathrm{P}<0.05 \mathrm{vs}$. SC; $\mathrm{P}<0.05$ vs. $2 \mathrm{VO}$; Fig. 5). These results indicate that exercise promotes the differentiation of progenitor cells into mature neurons in the $\mathrm{SGZ}$ of $2 \mathrm{VO}$ rats.

Treadmill exercise increases the expression of BDNF protein in the hippocampus. To determine the effect of exercise on 
A

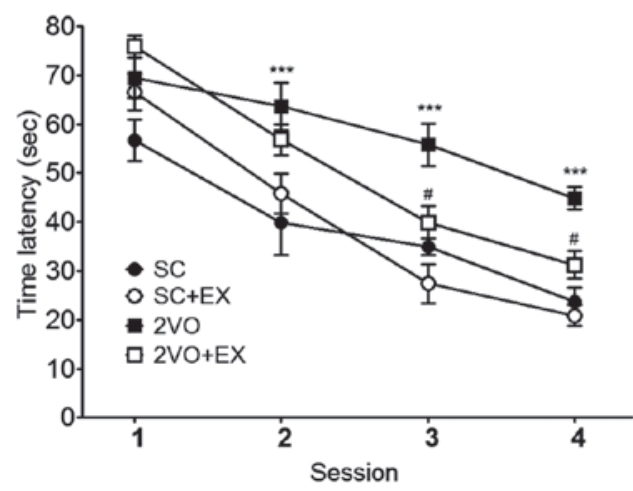

C

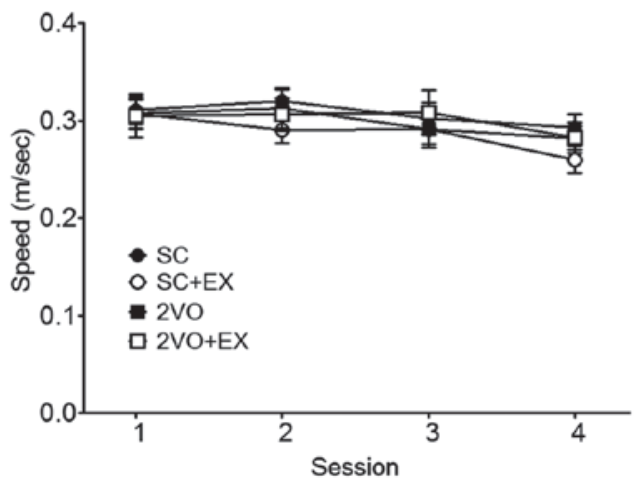

B

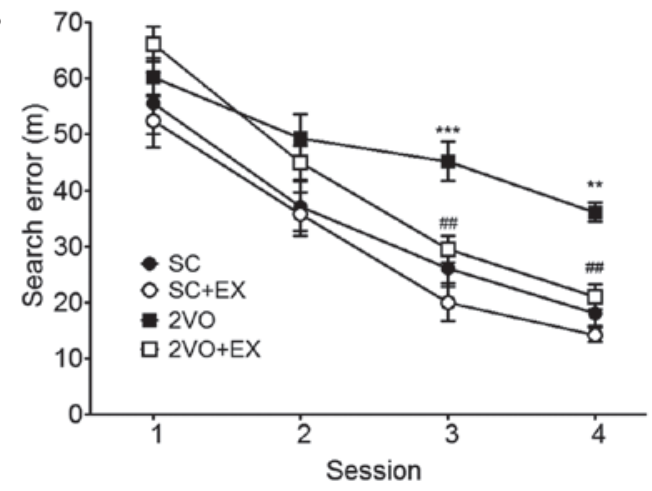

D

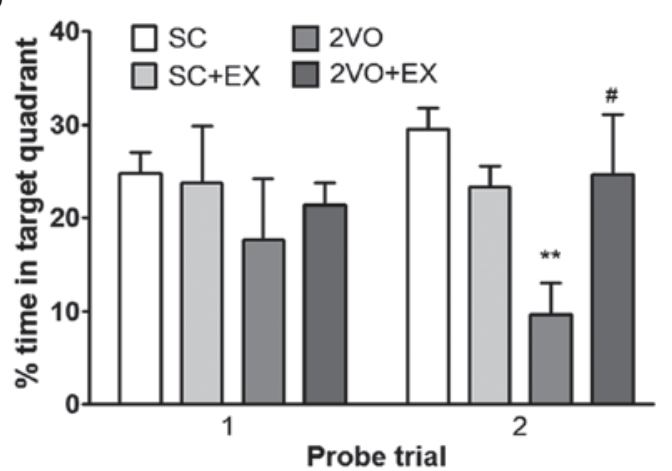

Figure 2. Effect of treadmill exercise on performance deficits induced by chronic cerebral hypoperfusion in rats in the Morris water maze test. Spatial memory evaluation using (A) time latency, (B) search error, (C) swimming speed, and (D) percentage of time spent in target quadrant. $\mathrm{n}=12-13 /$ group. ${ }^{* *} \mathrm{P}<0.01$, ${ }^{* * * *} \mathrm{P}<0.001$ vs. SC; ${ }^{\#} \mathrm{P}<0.05,{ }^{\# \#} \mathrm{P}<0.01$ vs. 2 VO. SC, sham-surgery group; $\mathrm{SC}+\mathrm{EX}$, sham-surgery group subjected to treadmill exercise (15 m/min, $30 \mathrm{~min} / \mathrm{day}$ for 4 weeks); 2VO, 2VO surgery group; 2VO+EX, 2VO-surgery group subjected to treadmill exercise (15 m/min, $30 \mathrm{~min} / \mathrm{day}$ for $4 \mathrm{weeks}$ ).

A
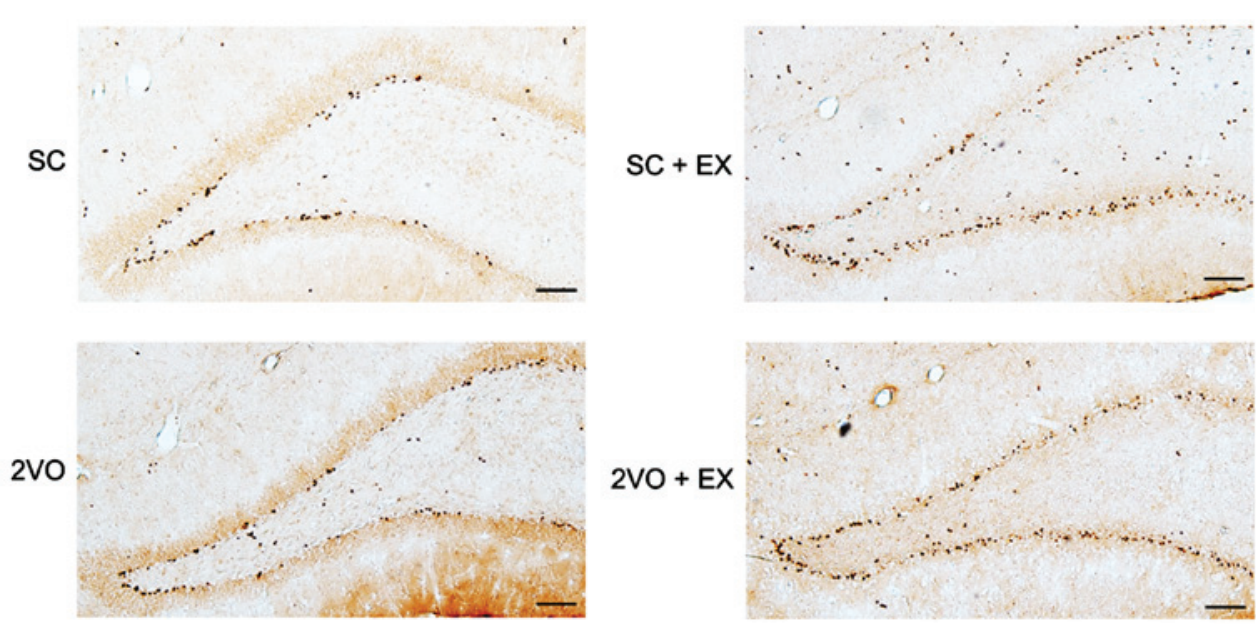

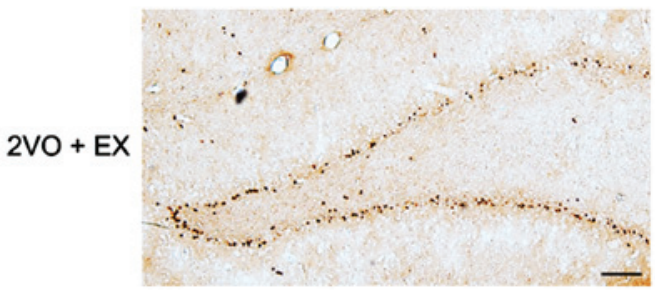

B

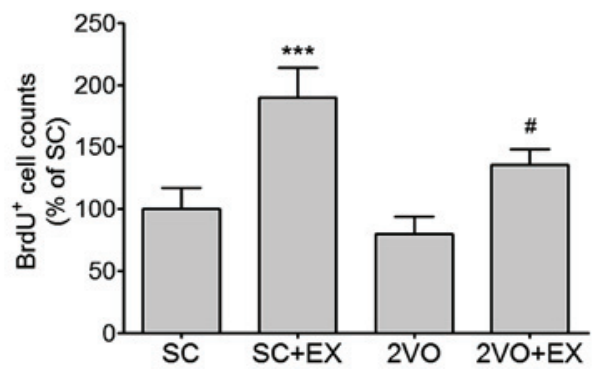

Figure 3. Effect of treadmill exercise on the cell proliferation in the SGZ. (A) Representative photomicrograph of BrdU immunostaining showing proliferating cells in the SGZ area 7 weeks after SC or 2VO surgery. Scale bars, $100 \mu \mathrm{m}$. (B) BrdU-stained cells were counted in the brain. Results are presented as the mean \pm standard error of the mean, $\mathrm{n}=8 .{ }^{* * *} \mathrm{P}<0.001$ vs. $\mathrm{SC} ;{ }^{*} \mathrm{P}<0.05$ vs. $2 \mathrm{VO}$. SC, sham-surgery group; SC+EX, sham-surgery group subjected to treadmill exercise (15 m/min, $30 \mathrm{~min} /$ day for 4 weeks); 2VO, 2VO surgery group; 2VO+EX, 2VO-surgery group subjected to treadmill exercise (15 m/min, $30 \mathrm{~min} /$ day for 4 weeks); SGZ, subgranular zone; BrdU, 5-bromo-2-deoxyuridine. 
A
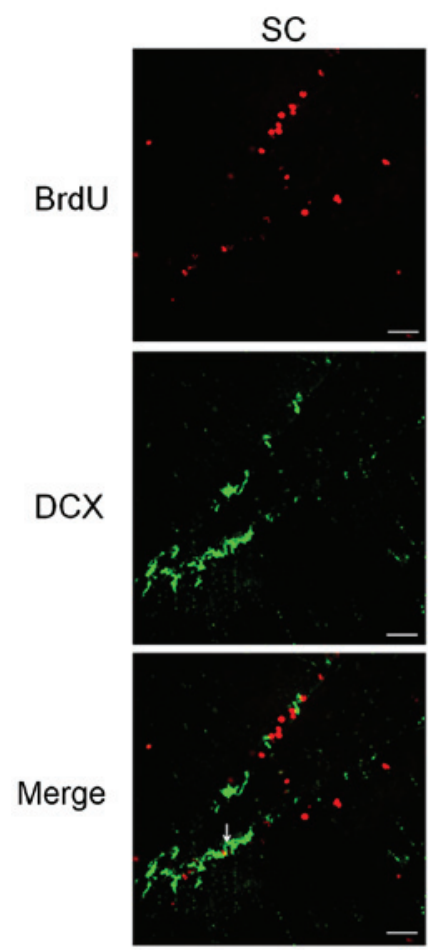
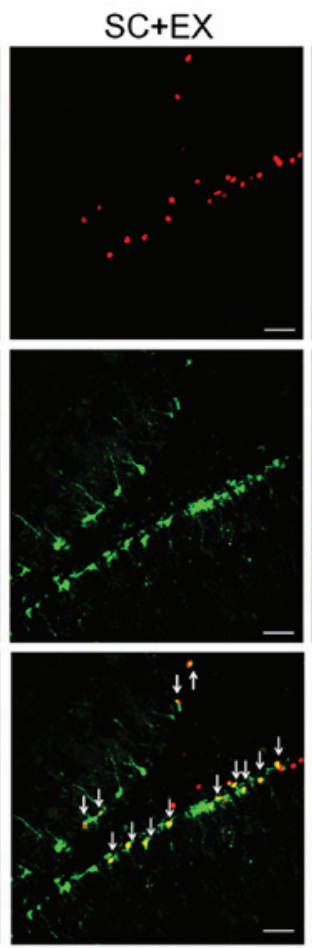

2VO
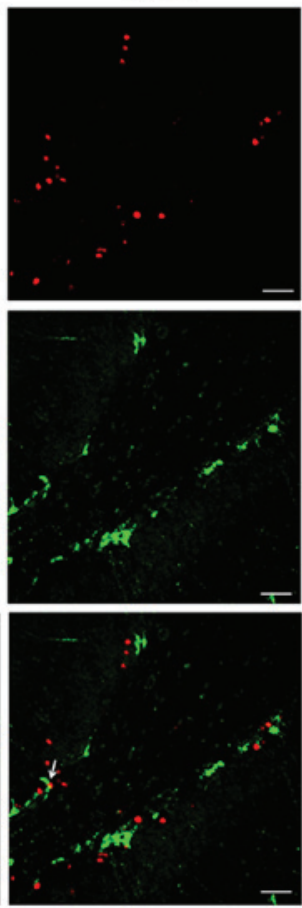

2VO+EX
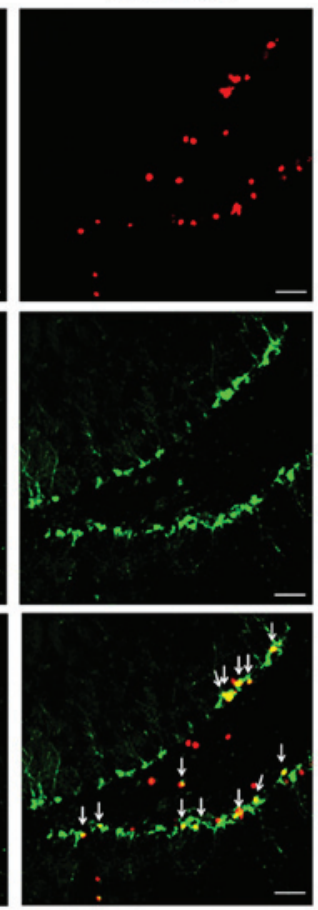

B

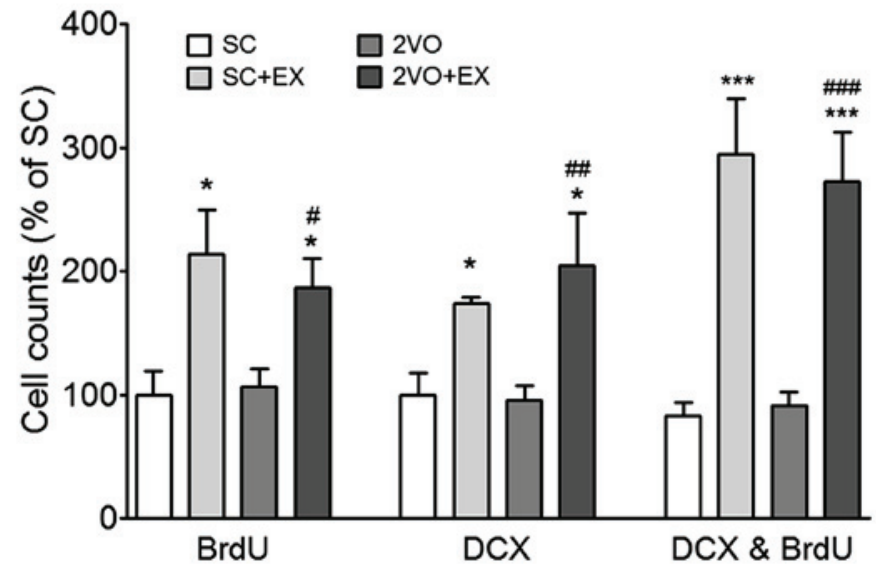

Figure 4. Effect of treadmill exercise on the proliferation of neural progenitor cells in the SGZ after CCH. (A) Representative photomicrograph of DCX or BrdU immunostaining showing proliferating cells in the SGZ area 7 weeks after 2VO surgery. DCX and BrdU coexpression in the SGZ is depicted as yellow staining after merging green (DCX) and red (BrdU) images. Arrows indicate cells showing double-staining for DCX and BrdU. Scale bars, $50 \mu \mathrm{m}$. (B) BrdU ${ }^{+}$, $\mathrm{DCX}^{+}$, and $\mathrm{DCX}^{+}$and $\mathrm{BrdU}^{+}$cells were counted in the hippocampal brain sections. Results are presented as the mean \pm standard error of the mean, $\mathrm{n}=8$. ${ }^{*} \mathrm{P}<0.05,{ }^{* * *} \mathrm{P}<0.001$ vs. SC; ${ }^{\#} \mathrm{P}<0.05,{ }^{\#} \mathrm{P}<0.01,{ }^{\# \#} \mathrm{P}<0.001$ vs. $2 \mathrm{VO}$. SC, sham-surgery group; SC+EX, sham-surgery group subjected to treadmill exercise $(15 \mathrm{~m} / \mathrm{min}, 30 \mathrm{~min} /$ day for 4 weeks); 2VO, 2VO surgery group; 2VO+EX, 2VO-surgery group subjected to treadmill exercise (15 m/min, $30 \mathrm{~min} / \mathrm{day}$ for 4 weeks); SGZ, subgranular zone; $\mathrm{CCH}$, chronic cerebral hypoperfusion; BrdU, 5-bromo-2-deoxyuridine; DCX, doublecortin.

the levels of expression of mature BDNF in the hippocampus, mature BDNF expression in the hippocampus was detected by western blot analysis (Fig. 6A). Mature BDNF expression in the hippocampus of the SC+EX and $2 \mathrm{VO}+\mathrm{EX}$ rats was increased compared with that observed for $\mathrm{SC}$ rats (all $\mathrm{P}<0.01$; Fig. 6B). Furthermore, the level of mature BDNF expression in $2 \mathrm{VO}$ rats was enhanced by exercise ( $\mathrm{P}<0.01$ vs. $2 \mathrm{VO}$, Fig. $6 \mathrm{~B})$.

Treadmill exercise increases the expression of the hippocampal phosphorylated CREB protein. Western blot analysis was used to determine the effect of exercise on the phosphorylation of CREB in the hippocampus (Fig. 7). Phosphorylated CREB expression was decreased in the hippocampus of $2 \mathrm{VO}$ rats $(\mathrm{P}<0.01$, Fig. 7$)$. Moreover, the decrease in the level of phosphorylated CREB in 2VO rats was reversed by exercise $(\mathrm{P}<0.01$ vs. 2VO, Fig. 7).

\section{Discussion}

To the best of our knowledge, this is the first study to demonstrate that the performance of forced treadmill exercise for 4 weeks after $\mathrm{CCH}$ increased cognitive function and hippocampal neurogenesis via the BDNF-pCREB pathway. Enhanced BDNF-pCREB signaling induced by exercise was beneficial, not only because it increased the number of new hippocampal neurons, but also because it reduced functional impairment in the $2 \mathrm{VO}$ group. Notably, treadmill exercise significantly increased cognitive function and hippocampal 
A
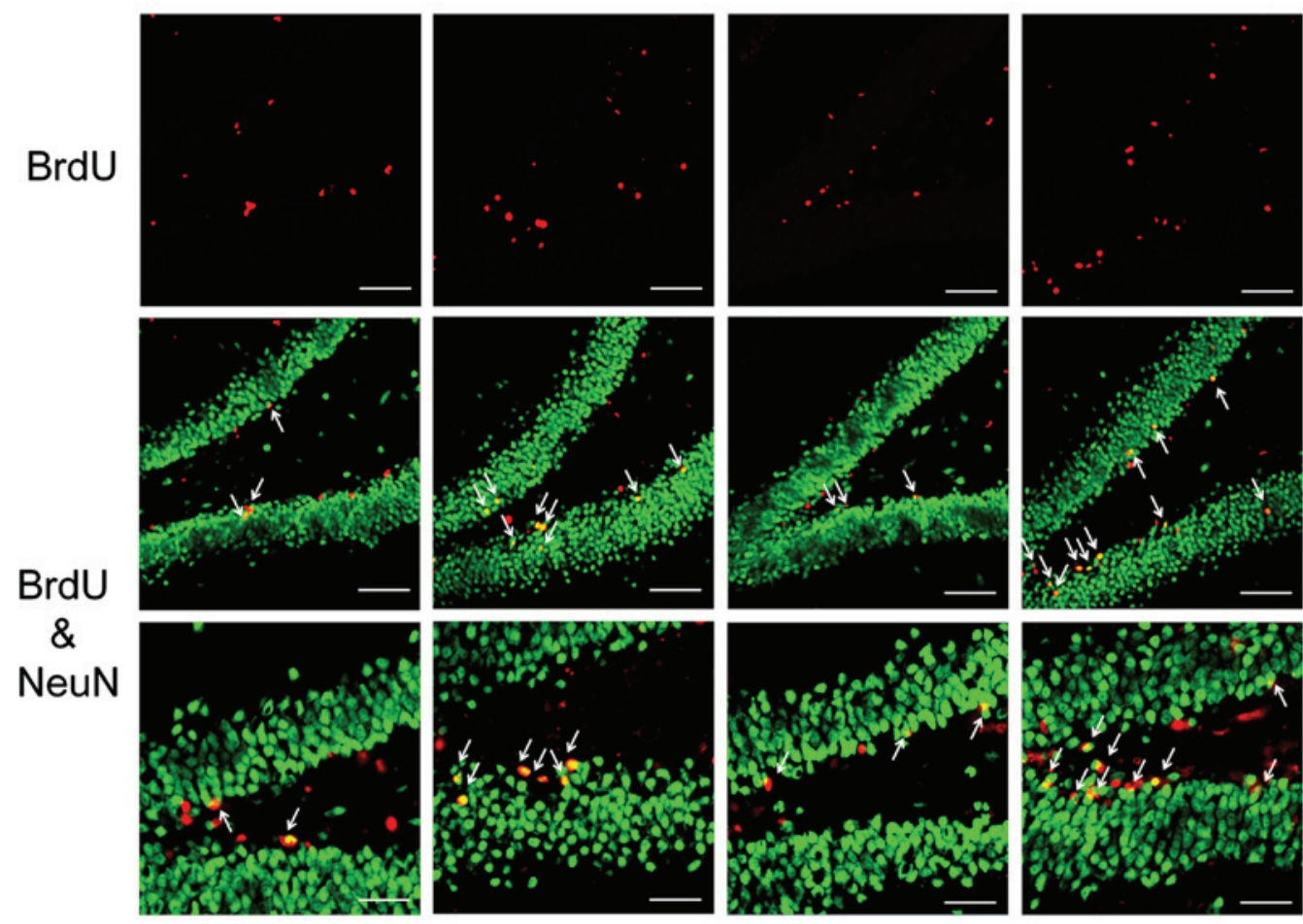

B

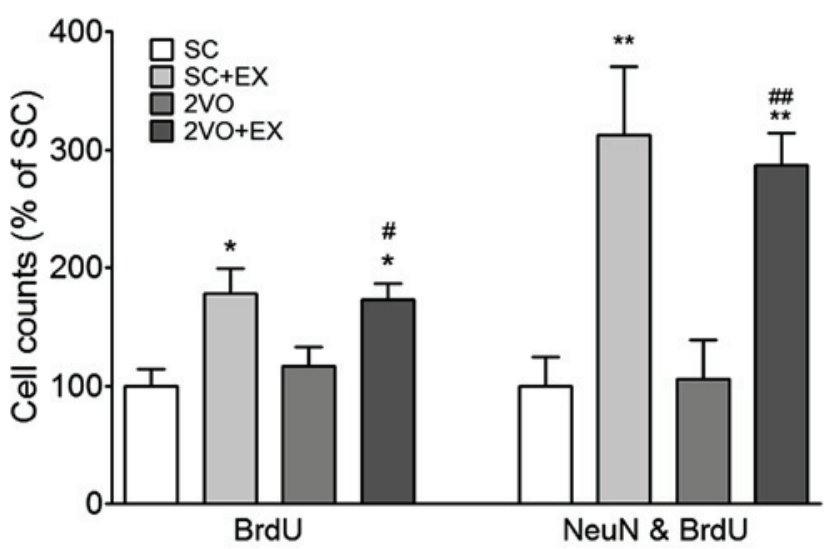

Figure 5. Treadmill exercise increased the differentiation of progenitor cell in the SGZ after 2VO surgery. (A) Representative photomicrograph of BrdU (red) and NeuN (green) double immunostaining showing matured newborn neurons in the SGZ at 4 weeks after 2 VO surgery. NeuN and BrdU coexpression in the SGZ is depicted as yellow staining after merging green (DCX) and red (BrdU) images. Arrows indicate cells showing double-staining for NeuN and BrdU. Scale bars, $80 \mu \mathrm{m}$ (upper and middle panel) or $40 \mu \mathrm{m}$ (lower panel). (B) $\mathrm{DCX}^{+}$and BrdU $\mathrm{C}^{+}$cells were counted in the brain. Results are presented as the mean \pm standard error of the mean, $\mathrm{n}=8 .{ }^{*} \mathrm{P}<0.05,{ }^{* *} \mathrm{P}<0.01$ vs. $\mathrm{SC} ;{ }^{\#} \mathrm{P}<0.05,{ }^{\# \#} \mathrm{P}<0.01$ vs. 2 VO. SC, sham-surgery group; SC+EX, sham-surgery group subjected to treadmill exercise ( $15 \mathrm{~m} / \mathrm{min}, 30 \mathrm{~min} /$ day for 4 weeks); 2VO, 2VO surgery group; 2VO+EX, 2VO-surgery group subjected to treadmill exercise (15 m/min, $30 \mathrm{~min} /$ day for 4 weeks); SGZ, subgranular zone; BrdU, 5-bromo-2-deoxyuridine.

neurogenesis in $2 \mathrm{VO}$ rats. In addition, decreased pCREB signaling in the $2 \mathrm{VO}$ group was reversed by treadmill exercise.

$\mathrm{CCH}$ is strongly correlated with the severity of memory dysfunction and the decline of cerebral blood flow in Alzheimer's disease, VaD and post-stroke hypoperfusion (35). It was previously demonstrated that $\mathrm{CCH}$ induces, oxidative stress in the hippocampus, hippocampal neurodegeneration, neuroinflammation and a reduction in cerebral blood flow, which results in memory impairment in the $2 \mathrm{VO}$ animal model $(11,30,34)$.

Exercise enhances cognitive function in a number of models of brain disease, such as delaying the cognitive decline associated with aging, preventing cognitive deficits in a variety of Alzheimer's disease models (36-38), modifying cognitive function in Parkinson's disease $(39,40)$, modulating cognitive deficits in Huntington's disease models (41-43), affording neuroprotective effects in models of chronic stress $(38,44,45)$, and improving functional recovery from traumatic brain injury $(38,45,46)$. A previous study has shown that forced treadmill exercise prevents oxidative stress and memory deficits after chronic cerebral hypoperfusion in the rat (14). Using exercise training as an upregulator of hippocampal neurogenesis, an in vivo imaging study performed in humans indicated a positive association between hippocampal-dependent cognitive performance and a change in cerebral blood volume (47). Furthermore, exercise intervention has been shown to improve performance in a neurogenesis-dependent cognitive test, the visual pattern separation task, in human subjects (48). Despite the technical limitations associated with the direct measurement of neurogenesis in the human brain, these two studies 
A
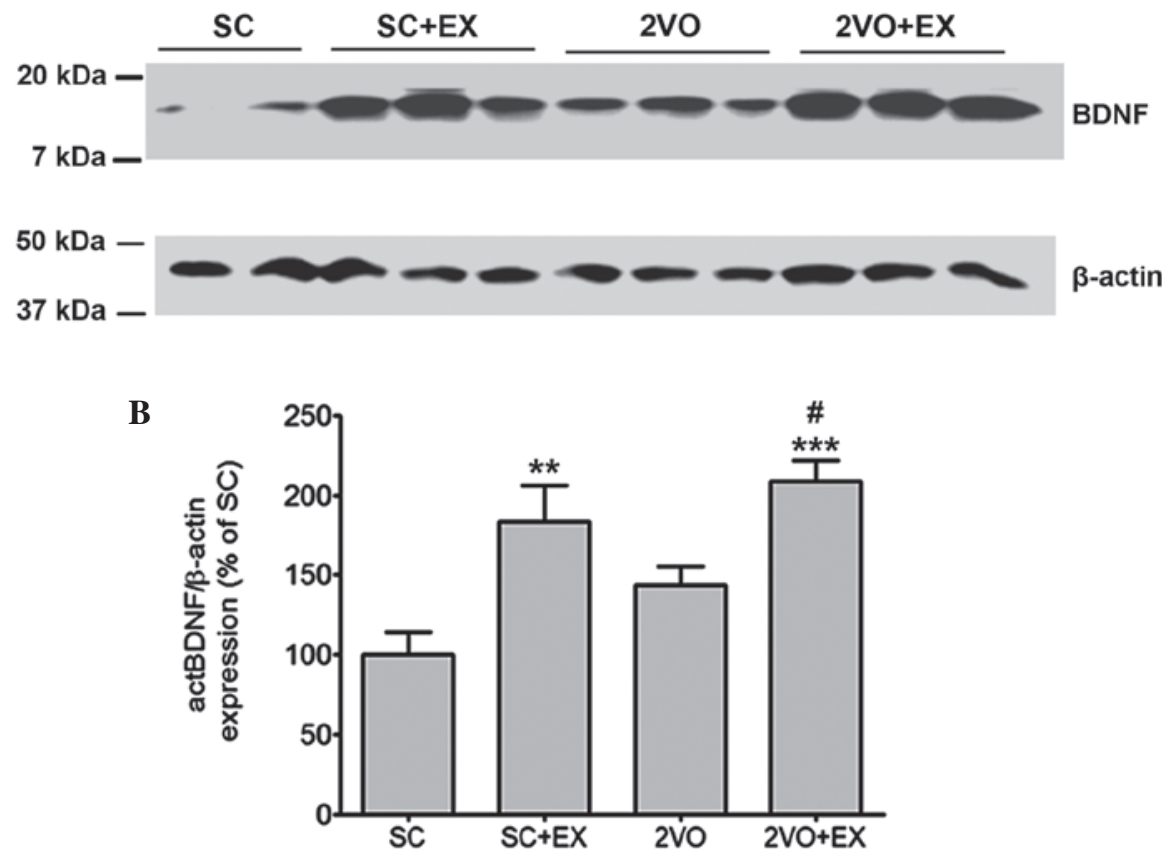

Figure 6. Treadmill exercise promotes mature BDNF expression. (A) Representative photomicrographs of western blot analysis showing BDNF levels in the hippocampus of rats in the SC, SC+EX, 2VO and 2VO+EX groups. (B) The intensity of each band was densitometrically determined and normalized against $\beta$-actin. Results are presented as the mean \pm standard error of the mean, $n=4 .{ }^{* *} \mathrm{P}<0.01,{ }^{* * *} \mathrm{P}<0.001$ vs. $\mathrm{SC} ;{ }^{*} \mathrm{P}<0.05$ vs. $2 \mathrm{VO}$. SC, sham-surgery group; SC+EX, sham-surgery group subjected to treadmill exercise (15 m/min, $30 \mathrm{~min} /$ day for 4 weeks); 2VO, 2VO surgery group; 2VO+EX, 2VO-surgery group subjected to treadmill exercise (15 m/min, $30 \mathrm{~min} /$ day for 4 weeks); BDNF, brain-derived neurotrophic factor.

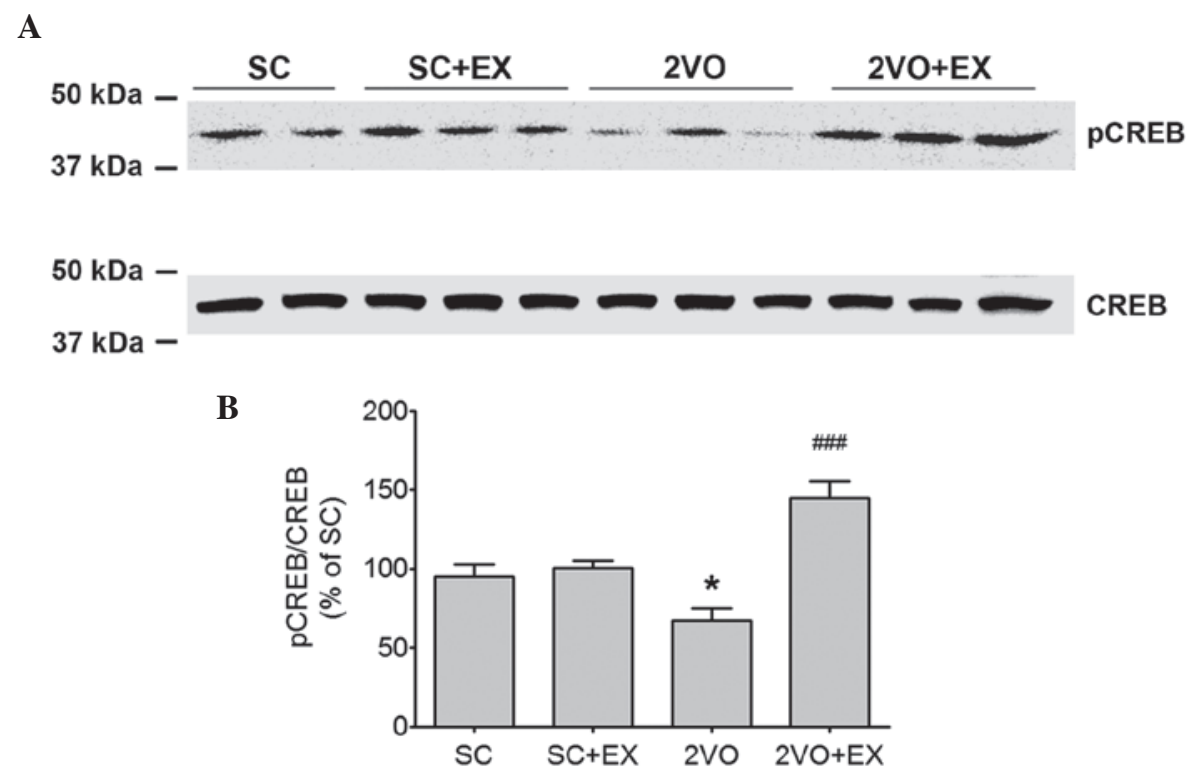

Figure 7. Treadmill exercise promotes pCREB expression in the 2VO group. (A) Representative photomicrographs of western blot analysis showing pCREB levels in the hippocampus of rats. (B) The intensity of each band was densitometrically determined and normalized against CREB. Results are presented as the mean \pm standard error of the mean, $\mathrm{n}=4$. ${ }^{*} \mathrm{P}<0.05$ vs. SC; ${ }^{\# \# "} \mathrm{P}<0.001$ vs. $2 \mathrm{VO}$. SC, sham-surgery group; SC+EX, sham-surgery group subjected to treadmill exercise ( $15 \mathrm{~m} / \mathrm{min}, 30 \mathrm{~min} /$ day for 4 weeks); $2 \mathrm{VO}, 2 \mathrm{VO}$ surgery group; $2 \mathrm{VO}+\mathrm{EX}, 2 \mathrm{VO}$-surgery group subjected to treadmill exercise $(15 \mathrm{~m} / \mathrm{min}, 30 \mathrm{~min} / \mathrm{day}$ for 4 weeks); pCREB, phosphorylated-cAMP-calcium response element binding protein.

suggest that new adult-born neurons in the hippocampus have a functional role in learning and memory in the human brain $(48,49)$.

Animal studies have suggested that enhanced hippocampal neurogenesis underlies the reported beneficial effects of exercise on cognitive function. Studies performed by van Praag et al showed that physical activity not only increased hippocampal neurogenesis $(16,50)$, but also improved MWM performance and selectively increased long-term potentiation in the dentate gyrus of 3-month-old mice (50). In addition to upregulating the neurogenic process, physical activity can also increase the capacity of neurons in the hippocampus to sustain synaptic plasticity and facilitate hippocampal-dependent learning in the same animals $(23,49)$. 
In the present study, the significant increase observed in the total population of neural progenitor cells and mature neurons identified as $\mathrm{BrdU}^{+}$and $\mathrm{DCX}^{+}$or $\mathrm{NeuN}^{+}$cells in animals that underwent treadmill exercise suggests increased hippocampal neurogenic activity in rats from the $2 \mathrm{VO}$ group. To the best of our knowledge, this is a novel finding.

A number of studies have attributed exercise-induced changes in central nervous system neurogenesis and cognitive function to $\operatorname{BDNF}(50,51)$. However, in addition to being crucial for controlling several brain functions, BDNF is particularly important for regulating hippocampal plasticity (52), which contributes to learning and memory $(40,53,54)$. Increased levels of this neurotrophin minimize ischemic neuronal death (55-60) and enhance hippocampal synaptic transmission (61-63).

Physical exercise increases the expression of hippocampal BDNF (64). Several studies have demonstrated that alterations in BDNF expression result from the activation/phosphorylation of the transcription factor, cAMP-response-element binding protein (CREB), following exercise (65-67). For example, in rats, exercise activates hippocampal CREB and the mitogen-activated protein kinase (MAPK) pathway (67). The MAPK cascade facilitates the phosphorylation of CREB $(65,68)$. CREB is involved in long-term plasticity (69) and memory (70), and its phosphorylation is involved in the activation of its target genes, including BDNF $(65,71)$.

In the present study, the expression of BDNF and the phosphorylation of CREB at the protein level was examined after exercise in a rat model of VaD. Western blotting results showed that $\mathrm{CCH}$ caused a decrease in the expression of pCREB. Treadmill exercise increased the expression of hippocampal mature BDNF and the phosphorylation of the CREB protein. Based on the combined findings of this study, it was hypothesized that physical exercise increases post-ischemic neurogenesis via the pCREB-dependent upregulation of BDNF in 2VO-induced $\mathrm{VaD}$. This evidence implies that physical exercise provides protection against cognitive impairment in VaD. Therefore, it was concluded that physical activity may prevent the development of $\mathrm{VaD}$ and could have important clinical implications for therapeutic intervention of $\mathrm{VaD}$.

\section{Acknowledgements}

This study was supported by the Konkuk University Medical Center Research Grant 2012 (grant no. 201210).

\section{References}

1. Román GC: Vascular dementia: Distinguishing characteristics, treatment and prevention. J Am Geriatr Soc 51 (Suppl Dementia 5): S296-S304, 2003.

2. Aggarwal NT and Decarli C: Vascular dementia: Emerging trends. Semin Neurol 27: 66-77, 2007.

3. Jellinger KA: Morphologic diagnosis of 'vascular dementia'-a critical update. J Neurol Sci 270: 1-12, 2008.

4. Erkinjuntti T, Román G, Gauthier S, Feldman H and Rockwood K: Emerging therapies for vascular dementia and vascular cognitive impairment. Stroke 35: 1010-1017, 2004.

5. de la Torre JC: Vascular risk factor detection and control may prevent Alzheimer's disease. Ageing Res Rev 9: 218-225, 2010.

6. Lin MS, Chiu MJ, Wu YW, Huang CC, Chao CC, Chen YH, Lin HJ, Li HY, Chen YF, Lin LC, et al: Neurocognitive improvement after carotid artery stenting in patients with chronic internal carotid artery occlusion and cerebral ischemia. Stroke 42: 2850-2854, 2011.
7. Naritomi H: Experimental basis of multi-infarct dementia: Memory impairments in rodent models of ischemia. Alzheimer Dis Assoc Disord 5: 103-111, 1991.

8. Ni J, Ohta H, Matsumoto $\mathrm{K}$ and Watanabe $\mathrm{H}$ : Progressive cognitive impairment following chronic cerebral hypoperfusion induced by permanent occlusion of bilateral carotid arteries in rats. Brain Res 653: 231-236, 1994.

9. Shibata M, Yamasaki N, Miyakawa T, Kalaria RN, Fujita Y, Ohtani R, Ihara M, Takahashi R and Tomimoto H: Selective impairment of working memory in a mouse model of chronic cerebral hypoperfusion. Stroke 38: 2826-2832, 2007.

10. Jiwa NS, Garrard P and Hainsworth AH: Experimental models of vascular dementia and vascular cognitive impairment: A systematic review. J Neurochem 115: 814-828, 2010.

11. Choi BR, Lee SR, Han JS, Woo SK, Kim KM, Choi DH, Kwon KJ, Han SH, Shin CY, Lee J, et al: Synergistic memory impairment through the interaction of chronic cerebral hypoperfusion and amlyloid toxicity in a rat model. Stroke 42: 2595-2604, 2011.

12. Ji HJ, Hu JF, Wang YH, Chen XY, Zhou R and Chen NH: Osthole improves chronic cerebral hypoperfusion induced cognitive deficits and neuronal damage in hippocampus. Eur J Pharmacol 636: 96-101, 2010.

13. Radak Z, Toldy A, Szabo Z, Siamilis S, Nyakas C, Silye G, Jakus $J$ and Goto $S$ : The effects of training and detraining on memory, neurotrophins and oxidative stress markers in rat brain. Neurochem Int 49: 387-392, 2006.

14. Cechetti F, Worm PV, Elsner VR, Bertoldi K, Sanches E, Ben J, Siqueira IR and Netto CA: Forced treadmill exercise prevents oxidative stress and memory deficits following chronic cerebral hypoperfusion in the rat. Neurobiol Learn Mem 97: 90-96, 2012.

15. Ogonovszky H, Berkes I, Kumagai S, Kaneko T, Tahara S, Goto S and Radák Z: The effects of moderate-, strenuous- and over-training on oxidative stress markers, DNA repair and memory, in rat brain. Neurochem Int 46: 635-640, 2005.

16. van Praag H, Christie BR, Sejnowski TJ and Gage FH: Running enhances neurogenesis, learning and long-term potentiation in mice. Proc Natl Acad Sci USA 96: 13427-13431, 1999.

17. Mattson MP: Neuroprotective signaling and the aging brain: Take away my food and let me run. Brain Res 886: 47-53, 2000.

18. Zhao C, Deng W and Gage FH: Mechanisms and functional implications of adult neurogenesis. Cell 132: 645-660, 2008.

19. Lucassen PJ, Meerlo P, Naylor AS, van Dam AM, Dayer AG, Fuchs E, Oomen CA and Czéh B: Regulation of adult neurogenesis by stress, sleep disruption, exercise and inflammation: Implications for depression and antidepressant action. Eur Neuropsychopharmacol 20: 1-17, 2010.

20. Briones TL, Suh E, Hattar H and Wadowska M: Dentate gyrus neurogenesis after cerebral ischemia and behavioral training. Biol Res Nurs 6: 167-179, 2005.

21. Arida RM, Scorza FA, Gomes da Silva S, Cysneiros RM and Cavalheiro EA: Exercise paradigms to study brain injury recovery in rodents. Am J Phys Med Rehabil 90: 452-465, 2011.

22. Ji JF, Ji SJ, Sun R, Li K, Zhang Y, Zhang LY and Tian Y: Forced running exercise attenuates hippocampal neurogenesis impairment and the neurocognitive deficits induced by whole-brain irradiation via the BDNF-mediated pathway. Biochem Biophys Res Commun 443: 646-651, 2014.

23. Vivar C, Potter MC, Choi J, Lee JY, Stringer TP, Callaway EM, Gage FH, Suh H and van Praag H: Monosynaptic inputs to new neurons in the dentate gyrus. Nat Commun 3: 1107, 2012.

24. Kobilo T, Yuan C and van Praag $\mathrm{H}$ : Endurance factors improve hippocampal neurogenesis and spatial memory in mice. Learn Mem 18: 103-107, 2011.

25. Verdelho A, Madureira S, Ferro JM, Baezner H, Blahak C, Poggesi A, Hennerici M, Pantoni L, Fazekas F, Scheltens P, et al: Physical activity prevents progression for cognitive impairment and vascular dementia: Results from the LADIS (Leukoaraiosis and Disability) study. Stroke 43: 3331-3335, 2012.

26. Coelho FM, Pereira DS, Lustosa LP, Silva JP, Dias JM, Dias RC, Queiroz BZ, Teixeira AL, Teixeira MM and Pereira LS: Physical therapy intervention (PTI) increases plasma brain-derived neurotrophic factor (BDNF) levels in non-frail and pre-frail elderly women. Arch Gerontol Geriatr 54: 415-420, 2012.

27. Scarmeas N, Luchsinger JA, Schupf N, Brickman AM, Cosentino S, Tang MX and Stern Y: Physical activity, diet and risk of Alzheimer disease. JAMA 302: 627-637, 2009.

28. Cotman CW, Berchtold NC and Christie LA: Exercise builds brain health: Key roles of growth factor cascades and inflammation. Trends Neurosci 30: 464-472, 2007. 
29. Cunha $\mathrm{C}$, Brambilla $\mathrm{R}$ and Thomas KL: A simple role for BDNF in learning and memory? Front Mol Neurosci 3: 1, 2010.

30. Kwon KJ, Kim MK, Lee EJ, Kim JN, Choi BR, Kim SY, Cho KS, Han JS, Kim HY, Shin CY and Han SH: Effects of donepezil, an acetylcholinesterase inhibitor, on neurogenesis in a rat model of vascular dementia. J Neurol Sci 347: 66-77, 2014.

31. Lee SH, Kim YH, Kim YJ and Yoon BW: Enforced physical training promotes neurogenesis in the subgranular zone after focal cerebral ischemia. J Neurol Sci 269: 54-61, 2008.

32. Sasaki H, Inoue T, Iso H and Fukuda Y: Recovery of visual behaviors in adult hamsters with the peripheral nerve graft to the sectioned optic nerve. Exp Neurol 159: 377-390, 1999.

33. Alaei H, Borjeian L, Azizi M, Orian S, Pourshanazari A and Hanninen O: Treadmill running reverses retention deficit induced by morphine. Eur J Pharmacol 536: 138-141, 2006.

34. Choi DH, Lee KH, Kim JH, Seo JH, Kim HY, Shin CY, Han JS Han SH, Kim YS and Lee J: NADPH oxidase 1, a novel molecular source of ROS in hippocampal neuronal death in vascular dementia. Antioxid Redox Signal 21: 533-550, 2014.

35. Ohta $\mathrm{H}$, Nishikawa $\mathrm{H}$, Kimura $\mathrm{H}$, Anayama $\mathrm{H}$ and Miyamoto $\mathrm{M}$ : Chronic cerebral hypoperfusion by permanent internal carotid ligation produces learning impairment without brain damage in rats. Neuroscience 79: 1039-1050, 1997.

36. Adlard PA, Perreau VM, Pop V and Cotman CW: Voluntary exercise decreases amyloid load in a transgenic model of Alzheimer's disease. J Neurosci 25: 4217-4221, 2005.

37. Dao AT, Zagaar MA, Levine AT, Salim S, Eriksen JL and Alkadhi KA: Treadmill exercise prevents learning and memory impairment in Alzheimer's disease-like pathology. Curr Alzheimer Res 10: 507-515, 2013

38. Pang TY and Hannan AJ: Enhancement of cognitive function in models of brain disease through environmental enrichment and physical activity. Neuropharmacology 64: 515-528, 2013

39. Ahlskog JE: Does vigorous exercise have a neuroprotective effect in Parkinson disease? Neurology 77: 288-294, 2011

40. Alonso M, Vianna MR, Depino AM, Mello e Souza T, Pereira P, Szapiro G, Viola H, Pitossi F, Izquierdo I and Medina JH: BDNF-triggered events in the rat hippocampus are required for both short- and long-term memory formation. Hippocampus 12 : 551-560, 2002

41. Pang TY, Stam NC, Nithianantharajah J, Howard ML and Hannan AJ: Differential effects of voluntary physical exercise on behavioral and brain-derived neurotrophic factor expression deficits in Huntington's disease transgenic mice. Neuroscience 141: 569-584, 2006.

42. Van Raamsdonk JM, Pearson J, Slow EJ, Hossain SM, Leavitt BR and Hayden MR: Cognitive dysfunction precedes neuropathology and motor abnormalities in the YAC128 mouse model of Huntington's disease. J Neuroscience 25: 4169-4180, 2005 .

43. Harrison DJ, Busse M, Openshaw R, Rosser AE, Dunnett SB and Brooks SP: Exercise attenuates neuropathology and has greater benefit on cognitive than motor deficits in the R6/1 Huntington's disease mouse model. Exp Neurol 248: 457-469, 2013.

44. Nagata K, Nakashima-Kamimura N, Mikami T, Ohsawa I and Ohta S: Consumption of molecular hydrogen prevents the stress-induced impairments in hippocampus-dependent learning tasks during chronic physical restraint in mice. Neuropsychopharmacology 34: 501-508, 2009.

45. Kim BS, Kim MY and Leem YH: Hippocampal neuronal death induced by kainic acid and restraint stress is suppressed by exercise. Neuroscience 194: 291-301, 2011.

46. Griesbach GS, Hovda DA and Gomez-Pinilla F: Exercise-induced improvement in cognitive performance after traumatic brain injury in rats is dependent on BDNF activation. Brain Res 1288: 105-115, 2009.

47. Pereira AC, Huddleston DE, Brickman AM, Sosunov AA, Hen R, McKhann GM, Sloan R, Gage FH, Brown TR and Small SA: An in vivo correlate of exercise-induced neurogenesis in the adult dentate gyrus. Proc Natl Acad Sci USA 104: 5638-5643, 2007.

48. Dery N, Pilgrim M, Gibala M, Gillen J, Wojtowicz JM, Macqueen $\mathrm{G}$ and Becker S: Adult hippocampal neurogenesis reduces memory interference in humans: Opposing effects of aerobic exercise and depression. Front Neurosci 7: 66, 2013

49. Yau SY, Gil-Mohapel J, Christie BR and So KF: Physical exercise-induced adult neurogenesis: A good strategy to prevent cognitive decline in neurodegenerative diseases? Biomed Res Int 2014: 403120, 2014.
50. van Praag H, Shubert T, Zhao $\mathrm{C}$ and Gage FH: Exercise enhances learning and hippocampal neurogenesis in aged mice. J Neurosci 25: 8680-8685, 2005

51. Alomari MA, Khabour OF, Alzoubi KH and Alzubi MA: Forced and voluntary exercises equally improve spatial learning and memory and hippocampal BDNF levels. Behav Brain Res 247: 34-39, 2013

52. Naylor AS, Persson AI, Eriksson PS, Jonsdottir IH and Thorlin T: Extended voluntary running inhibits exercise-induced adult hippocampal progenitor proliferation in the spontaneously hypertensive rat. J Neurophysiol 93: 2406-2414, 2005.

53. Alonso M, Vianna MR, Izquierdo I and Medina JH: Signaling mechanisms mediating BDNF modulation of memory formation in vivo in the hippocampus. Cell Mol Neurobiol 22: 663-674, 2002.

54. Mizuno M, Yamada K, Olariu A, Nawa $\mathrm{H}$ and Nabeshima $\mathrm{T}$ : Involvement of brain-derived neurotrophic factor in spatial memory formation and maintenance in a radial arm maze test in rats. J Neurosci 20: 7116-7121, 2000.

55. Ferrer I, Ballabriga J, Marti E, Pérez E, Alberch J and Arenas E: BDNF up-regulates TrkB protein and prevents the death of CA1 neurons following transient forebrain ischemia. Brain Pathol 8: 253-261, 1998.

56. Ferrer I, Krupinski J, Goutan E, Martí E, Ambrosio S and Arenas E: Brain-derived neurotrophic factor reduces cortical cell death by ischemia after middle cerebral artery occlusion in the rat. Acta Neuropathol 101: 229-238, 2001.

57. Kiprianova I, Freiman TM, Desiderato S, Schwab S, Galmbacher R, Gillardon F and Spranger M: Brain-derived neurotrophic factor prevents neuronal death and glial activation after global ischemia in the rat. J Neurosci Res 56: 21-27, 1999.

58. Schäbitz WR, Schwab S, Spranger M and Hacke W: Intraventricular brain-derived neurotrophic factor reduces infarct size after focal cerebral ischemia in rats. J Cereb Blood Flow Metab 17: 500-506, 1997.

59. Yamashita K, Wiessner C, Lindholm D, Thoenen $H$ and Hossmann KA: Post-occlusion treatment with BDNF reduces infarct size in a model of permanent occlusion of the middle cerebral artery in rat. Metab Brain Dis 12: 271-280, 1997.

60. Zhang Y and Pardridge WM: Neuroprotection in transient focal brain ischemia after delayed intravenous administration of brain-derived neurotrophic factor conjugated to a blood-brain barrier drug targeting system. Stroke 32: 1378-1384, 2001.

61. Vaynman S, Ying Z and Gomez-Pinilla F: Hippocampal BDNF mediates the efficacy of exercise on synaptic plasticity and cognition. Eur J Neurosci 20: 2580-2590, 2004.

62. Vaynman S, Ying Z and Gomez-Pinilla F: Interplay between brain-derived neurotrophic factor and signal transduction modulators in the regulation of the effects of exercise on synaptic-plasticity. Neuroscience 122: 647-657, 2003.

63. Vaynman S, Ying Z and Gómez-Pinilla F: Exercise induces BDNF and synapsin I to specific hippocampal subfields. J Neurosci Res 76: 356-362, 2004.

64. Molteni R, Ying Z and Gómez-Pinilla F: Differential effects of acute and chronic exercise on plasticity-related genes in the rat hippocampus revealed by microarray. Eur J Neurosci 16: 1107-1116, 2002.

65. Griesbach GS, Hovda DA, Molteni R, Wu A and Gomez-Pinilla F: Voluntary exercise following traumatic brain injury: Brain-derived neurotrophic factor upregulation and recovery of function. Neuroscience 125: 129-139, 2004.

66. Vaynman S, Ying Z and Gomez-Pinilla F: The select action of hippocampal calcium calmodulin protein kinase II in mediating exercise-enhanced cognitive function. Neuroscience 144: 825-833, 2007.

67. Shen H, Tong L, Balazs R and Cotman CW: Physical activity elicits sustained activation of the cyclic AMP response element-binding protein and mitogen-activated protein kinase in the rat hippocampus. Neuroscience 107: 219-229, 2001.

68. Finkbeiner S, Tavazoie SF, Maloratsky A, Jacobs KM, Harris KM and Greenberg ME: CREB: A major mediator of neuronal neurotrophin responses. Neuron 19: 1031-1047, 1997.

69. Abel T and Kandel E: Positive and negative regulatory mechanisms that mediate long-term memory storage. Brain Res Brain Res Rev 26: 360-378, 1998

70. Silva AJ, Kogan JH, Frankland PW and Kida S: CREB and memory. Annu Rev Neurosci 21: 127-148, 1998.

71. Finkbeiner S: Calcium regulation of the brain-derived neurotrophic factor gene. Cell Mol Life Sci 57: 394-401, 2000. 